\title{
El ideario político de Roy Campbell y la representación de la Guerra Civil española en su obra poética*
}

\author{
Luis Javier Conejero Magro \\ Universidad de Extremadura \\ conejero.lj@gmail.com
}

https://dx.doi.org/10.12795/futhark.2013.i08.06

\begin{abstract}
In this article, Roy Campbell's poems inspired by the Spanish Civil War are revisited and re-examined. Their war images and literary references to this conflict are analysed in the light of the poet's own political ideology. The conclusion is that the contrast between the exaggerated idealisation to which the rebels and their deeds are subjected, and the degree of degradation that those in favour of the Republic reach in their poetic representation is such that it transforms most of its lines into a quasi-Manichean or moralityplaylike pamphlet.

Key words: Roy Campbell, Spanish Civil War, war literature, war poetry, literature of the Thirties.

Resumen: En este artículo, se revisa y examina la poesía de Roy Campbell inspirada en la Guerra Civil española. Se analizan las imágenes bélicas y las referencias literarias de este conflicto desde la perspectiva de la propia ideología del poeta. La conclusión que se extrae es que el contraste entre la idealización exacerbada que se hace de los rebeldes y sus hechos, y el nivel de degradación que alcanzan quienes están a favor de la República en su representación poética, es tal que transforma la mayor parte de sus versos
\end{abstract}

*Deseo expresar mi agradecimiento a Ramón López Ortega y José Luis Oncins Martínez, por su inestimable ayuda en la realización de este artículo, que forma parte de un proyecto más amplio en el que participo bajo su dirección y tutela. 


\section{Datos eclécticos de deducción, diversidad y expansión}

En la diversión y dispersión de palabras alguna vez, o todavía existentes, así como en las de nueva creación, resultan especialmente llamativas aquellas que se asemejan sin haber tenido anteriormente parentesco alguno (vid. Whorf 1963: 220-230). Lo que parece casi imposible es, naturalmente, delimitar este hecho, tan fundamental, para la clasificación de las lenguas. Tradicionalmente se ha atendido a dos principios de investigación: por una parte a las raíces de formación de palabras, y por otra parte, a la clasificación tipológica de ellas (cf. Manteufel \& Schiepek 1998: 130-145). Un ejemplo sería el generativismo, que desde sus concepciones innatistas promueve que el alemán sea una lengua de orden S-V-O en la estructura superficial y S-O-V en la profunda, en tanto que el español sería en todo caso de orden S-V-O.

Nosotros, por nuestra parte, creemos conveniente recrear en el presente artículo aquellas palabras que por su idiosincrasia, presentan mayor dificultad en su clasificación debido a factores pseudosemánticos, a la incorporación de estructuras secundarias o a adaptaciones ortográficas y dialectales, entre algunas de las posibilidades (vid. Theo \& Cutter 1971: 10ss.; Traub 1994: 67). Por poner un ejemplo, y antes de adentrarnos en cuestiones más avanzadas, nos referiremos a la palabra Fas(e)nacht, que considerada un préstamo, reflecta numerosas variantes en lengua alemana:

Fasching, Fasnacht, Fasenacht, Fasenächten, Foosnacht (Ansbach), Foosenoocht (Ingolstadt y región de Loisach), Foosenachtn (región de Ammer), Foschen (Passau), Foscheng (región del Donau), Fasnet (región del río Mindel).

Por su historia, la referida palabra Fasching fue adoptada por la nobleza también en la ciudad de Viena en lugar de Fasenacht durante el siglo diecinueve e imitada por el joven rey de Baviera. En muchos de estos casos, una mirada a las formas precedentes debería concienciarnos de estos cambios (alem. Fasching < mhd. vaschanc; Fasenacht $<\mathrm{mdh}$. Vaselen, alem.sich fortpflanzen), si bien en la actualidad no se muestra como la única posibilidad. Así, la Fashion Week de Madrid, Fashion Lovers en Facebook, Fashion Show Mall, Fashion Outlets, ser fashion o Fashion Victim pueden ser considerados semianglicismos, tomados para expresar diversos contenidos de moda, gustos o tendencias, convirtiéndose, por lo general, en "préstamos semánticos" (vid. J. Sudo 2007: 37). Si bien, en la mayoría de los casos las palabras procederían de una misma protolengua germánica, por lo que directamente pasan a

Futhark 8 (2013) Castro, La evolución de las "Stammbildungen", 69-85 ISSN 1886-9300 
denominarse "germanismos", otros son considerados "préstamos exteriores" (Yule 2007: 45 ss.):

p. ej.:bigote (al. bei got, por Dios), blanco (germ. blank), bregar (got. bríkan), brindis (del al. bring dir's, yo te lo ofrezco, escanciar (gót. Skankjan), espía (gót. spaíha), espuela(del ant. espuera, y éste del gót. *spaúra; cf. nórd. spori ya. al. ant. sporo), guante (franco. want), guerra (del germ. *werra, pelea, discordia; al. ant. wërra, neerl. medio warre), rico (gót. reiks), rueca (germ. rokko), yelmo (del germ.cf. a. al. ant. e ingl. ant. hëlm) ${ }^{1}$.

Sin embargo, son otros muchos los casos en que se origina cierta confusión. Porque, ¿qué ocurre en el caso de nuevas formaciones como Handy en alemán?, ¿podría afirmarse que sea éste un préstamo directo tomado del inglés, como, en general, se piensa? Nos proponemos delimitar determinados nexos lingüísticos en vocablos relativos a la morfología (vocales, consonantes, nombres y verbo) de las lenguas en entornos de ámbito social y económico, al ser éstos los más representativos de las culturas germánica y románica. Nos centraremos particularmente en mostrar vocablos vagos e imprecisos y, particularmente, en casos de evolución constante, al parecernos los más interesantes por su ambigüedad, al no poder ni siquiera ser considerados préstamos integrales o xenismos, y que, por lo general, no se adaptan fácilmente a la lengua entrante (Napoli Jo, en 1996: 91-92). Del mismo modo, acotaremos aquellos que han experimentado transformaciones dentro de una misma lengua y, por ello, causan desacuerdo.

\section{Parentescos aparentes o "Scheinanglizismus"}

Normalmente muchos de los vocablos que suenan de forma similar a otra lengua nos hacen creer que son préstamos de la misma. A estas expresiones se las denomina "pseudos-préstamos". Si retomamos el ejemplo Handy, se confirma mediante su búsqueda fonológica en tres diccionarios, que es un préstamo ilusorio, ya que además mobilphoneo cellular phonees la palabra empleada en países de lengua inglesa (Glinz 1994: 34-56).

Los préstamos germánicos entran en dos épocas: una en la Hispania primitiva, donde se introdujeron germanismos a través del latín, bien directamente, en la invasión germánica como jabón, tejón, arpa, guerra, yelmo, dardo, albergue, estribo, espuela, falda, cofia, etc. La otra época es la de los germanismos modernos o préstamos del alemán al castellano, así en el siglo de oro entraron: bigote, trincar, brindis, chambergo. En el XIX y XX: blocao, sable, obús, blindar, feldespato, blendam, cinc, níquel, vivencia y lexías compuestas del tipo visión del mundo...

Futhark 8 (2013) Castro, La evolución de las "Stammbildungen", 69-85 ISSN 1886-9300 


\subsection{Posibles parentescos surgidos de forma independiente o por contacto con una tercera lengua}

La etimología de la palabra familia (alem. Familie) no ha podido ser establecida con exactitud. Hay quienes afirman que proviene del latín fama (hambre) y otros del término famulus (sirviente). Por eso, se piensa que, en sus orígenes, se utilizaba el concepto familia para referirse al conjunto de esclavos y criados propiedad de un solo hombre. En subsiguientes apartados presentamos una clasificación de supuestos términos de parentesco.

\subsubsection{El alomorfo de formación de plural -s}

El alomorfo $-s$ es objeto de nuestro estudio, pues su empleo depende directamente del tipo de raíz para la formación del plural. Originariamente la $-s$ adoptaba una estructura repetitiva en:

raíces con la última sílaba postónica terminada en -en o-el: p. ej. Jung[en](s), Mädel(s), Kumpel(s), Onkel(s);

sonido final vocálico de palabras extranjeras o formaciones con sufijos pseudo-extranjeros: p. ej. Mama(s), Tee(s), Nazi(s), Auto(s), Zulu(s), Ossi(s), Wessi(s), Realo(s), Fundi(s)

palabras extranjeras con acentuación final: p. ej. Karton(s), Park(s)

Observaciones: si bien es cierto que la $-s$ se ha impuesto en una serie de idiomas en vivo contacto con el alemán (p.ej. ingles, francés, español) como morfema único de plural, es interesante observar que el alemán en sufijaciones de nuevo tipo (Ossi, Wessi, Realo, Fundi, Schlaffi, etc.) también opta por $-s$ como morfema único de plural. Es más, con incorporaciones de variedades dialectales y/o coloquiales de su propia área lingüística (p.ej. Jung, Mädel) el alemán actual procede del mismo modo, ignorando sus propios hábitos morfológicos ( $-n$ para Junge, $-\varnothing$ para diminutivos dialectales:Mädel) y tratándolos como si fueran préstamos. Considérense también las sobredeterminaciones del tipo Spaghettis ( Spaghetti ya es plural en italiano!).

A partir de mediados del siglo $X X$ la $-s$ se extendió a otras formas fonológicas, como p. ej. Sputniks, a acrónimos como PCs, Profs... Algunas palabras extranjeras sustituyeron su alomorfo de plural por la $-s$, así Lexikons, Spaghettis, Brokkolis, Tabletts, contrastando con otras que adoptaron el préstamo manteniendo el morfema cero del alemán (con

Futhark 8 (2013) Castro, La evolución de las "Stammbildungen", 69-85

ISSN 1886-9300 
exclusión del dativo plural, en donde se ha seguido adoptando la terminación de caso, p. ej.:den Managern wird zu leicht vertraut):

alem. sg.: der Manager>pl.: die Manager (ingl. the managers, esp. los managers)

alem. sg.: der Dealer> pl.: die Dealer(ingl. the dealers, esp. los dealers)

(Cit. en Rüdinger 1992: 143ss.)

No obstante, las siguientes palabras no son de origen semántico inglés, esto es, no las consideraremos neologismos, si bien mantienen el parecido sonoro, presentado la posibilidad de asimilación de la $-s$ en el plural:

Lift(s) = ascensor, Twen(s) = alguien que está en los veinte (como extension de Teen[ager]), Showmaster(s)= anfitrión en un talk show, Party Service(s) = compañía que ofrece comida en ocasiones especiales, tales como Wedding(s) = bodas y cumpleaños, Dressman= modelo masculino $>$ excepción, pl. men, City(s) > también Cyties = centro de la ciudad (en ingl. city centre/downtown).

Aunque se conserven las formas de plural de sufijos tradicionales estandarizadas, se aprecia una clara tendencia a adoptar la $-s$ como morfema de plural principal en nuevos tipos de formación, estableciéndose de tal manera un rasgo moderno de parentesco/convergencia.

Resultan evidentes las influencias del inglés sobre la morfosintaxis y la morfología alemanas. ${ }^{2}$ Nos limitamos aquí a mostrar dos ejemplos evidentes: Das macht Sinn (ingl. That makes sense) versus Das hat Sinn / Das ist sinnvoll; * In 2004 konnte das Unternehmen seine Gewinne im operativen Geschäft verdoppeln.

2 Y sobre la española. Léase el siguiente razonamiento: $<<[\ldots]$ Las semejanzas entre los dos idiomas no se limitan a la gramática. Hay muchísimas palabras que salen de la misma fuente, el idioma latín. Casi todos los nombres en inglés que terminan en tion y ty provienen del latín. Las palabras con estos sufijos se identifican muy fácilmente por el hispano. Por ejemplo: nation, dedication, liberty, ability. Los adjetivos que terminan en -ous, como por ejemplo rigorous, famous, etc., no representan ninguna dificultad. $Y$ hay verbos en inglés que terminan en -ate (regulate, operate, moderate, etc.) que son los mismos que sus semejantes en el castellano. Pero, aquí hay trampas... No todas las palabras son las mismas. No es posible dar una lista. Hay que ir aprendiendo poco a poco para evitar los errores que comete "La Cuatro" cuando "destroza" el inglés con inventos como ${ }^{*}$ medicination, " perfectamently, etc. Sería una gran cosa si se pudiesen entender todas las palabras del inglés como se entienden las palabras confirmation y liberty. La dificultad está en que no todas las palabras del inglés vienen del latín. El inglés es un idioma germánico. En sus orígenes era uno de entre muchos idiomas que llegaron a ser los idiomas alemán, holandés, y los idiomas escandinavos>> (Cit. en http://www.abcdatos.com).

Futhark 8 (2013)

Castro, La evolución de las "Stammbildungen", 69-85

ISSN 1886-9300 
Pero el fenómeno al que nos remitimos se produce con mucha frecuencia en númerosas formaciones del francés y español internacional. Pueden considerarse "préstamos deslexicalizados", es decir, se emplean con un significado distinto al que tienen en la lengua original o son simplemente inexistentes en ella -constituyendo este último el supuesto más extremo-:

Baby-foot $=$ ser un as del fútbol (ingl. table-top football soccer), baskets = tennis shoes,sneakers (de: basketball shoes), building = edificio (a multi-story apartment building), camping $=$ en el sentido decampground, charter $=$ significando low-cost [adj.], faire le forcing $=$ to pile on a lot of pressure, fixing =cotización en bolsa (ingl. a quotation - stock exchange use), footing = jogging (como probable fuente del español)... ${ }^{3}$

$\mathrm{Y}$, en menor medida se hace extensivo a otros idiomas (cf. Oksaar 2003: 70-72 y Orwin 1994: 72). Dan cuenta de ello el portugués brasileño, el croata, el danés, el noruego, el holandés, el ruso, el chino mandarín o el judío de América, entre otros. Mostramos una corta relación que hace explícita referencia a estos vocablos:

Port. Braz.:

Outdoor $=$ cartelera publicitaria (billboard en Inglaterra) .

Croata:

El símbolo @ se emplea con sentido de Monkey (esp. mono; croata majmun).

Danés:

Flute $=$ baguette -existente también en castellano como préstamo, Butterfly = bow-tie, spanking = adquiere el sentido metafórico de having to face the music (término empleado en casos de corrupción).

Holandés:

Bandrecorder $=$ con el sentido original de tape recorder (-híbrido de formación con representación fonética del inglés [ae] -).

Noruego:

3 Un caso particular son los nombres de marcas que se utilizan para denotar el producto típico de las mismas, p. ej. alem. Tempo - esp. Kleenex para pañuelos de papel, esp. Reebook para designar botas deportivas. Otro ej. en esp. es la generación nintendo. Representan por antonomasia procesos formativos tanto cualitativos como cuantitativos, siendo nuevas palabras físicamente y obteniendo un nuevo significado respectivamente.

Futhark 8 (2013) Castro, La evolución de las "Stammbildungen", 69-85

ISSN 1886-9300 
Smoking = vestimenta semiformal -existente en francés (en inglés tuxedo)-, aircondition= airconditioning, una alternativa a Klimanlegg, traducción del préstamo alemán Klimaanlage.

Sueco:

Freestyle = walkman (puede deberse a una marca).

Ruso:

Shaping $=$ aerobics (empleada para ejercicios de forma body shaping).

Mandarín taiwanés:

Xiao kei-si = xiao significa small (pequeño) y kei-si representa la transliteración del inglés case. La expression viene a significar that's no big problem procede de manuales de enseñanza del inglés-.

Sefardí:

Stuffed Derma $=$ Kishke - plato que recibe el nombre inglés sin llamarse así-.

No queremos olvidarnos en este apartado los plurales onomatopéyicos, aquellas interjecciones adaptadas del inglés y que presentan muchas dificultades por ser (relativamente) recientes. ${ }^{4}$ Un ejemplo es bum (interjección onomatopéyica y adaptación de boom) / bums; en Argentina el búmeran (asimismo en Ecuador o México) / los búmeran; bumerán en España y en otras zonas de América / bumeranes (cf. Trudgill 2001: 110ss.).

\subsubsection{Preposiciones compuestos y sintagmas preposicionales abstractos}

En su diversidad el idioma alemán, inglés y español usan preposiciones (tomadas del latín) delante de un sustantivo para decir que "algo" está en la casa o in the house, detrás de la casa o behind the house, etc. La particularidad del alemán es la marcación de caso de los sustantivos.

\footnotetext{
${ }^{4}$ Los queremos denominar plurales dudosos. Son numerosos: baladi / baladies; balé / balés; bantú / bantúes; barman / bármanes; bajoplato / bajoplatos; baobab (árbol africano)/baobabs. Generalmente terminan en $i$ o $u$ tónicas, por lo que suelen hacer el plural en -s, -es, siendo considerada esta última forma la más culta. Existen asimismo los plurales dudosos derivados de latinismos: ratio / ratios; lapsus / lapsus; vademécum / vademécums; item / items; plus / pluses... O derivados del inglés blue jean / bluyín > bluyínes.
}

Futhark 8 (2013) Castro, La evolución de las "Stammbildungen", 69-85 ISSN 1886-9300 
Pensamos, en esta dirección, en la existencia de neologismos, tanto cualitativos como cuantitativos, que se multiplicaron a lo largo de la segunda mitad del S. XX. Es complejo definirlos debido a la procedencia de tesitura mixta. Éstos son algunos de ellos: im Anschluß an (ingl. subsequent to, palabra alemana que, en un principio en el contexto político, significa unión, reunión o anexión; im Gefolge von (ingl. in the wake of). ${ }^{5}$ Im Rahmen + Gen. (ingl. in the course of), unter Zuhilfenahme + Gen.(with the help of $)^{6}$ y unter/bei Berücksichtigung + Gen o unter Berücksichtigung dessen, con su carácterística combinación de palabras, son considerados compuestos de evolución. ${ }^{7}$

\subsubsection{Elementos gramaticales implícitos en la coherencia textual}

El término de correferencia, indicativo de que la identidad de referencia -objeto de reanudación del discurso textual- esté comprendida en las expresiones de reanudación de ese discurso y su correspondencia con el objeto portador de dicha referencia, nos lleva a considerar en este apartado a personas, objetos, hechos, acontecimientos, acciones, supuestos de imaginación, etc. (vid. Maturana 1998: 73).

Los pronombres como símbolo de la referencia de identidad se manifiestan normalmente en el relato en tercera persona (er, sie, es; sie). El pronombre demostrativo es otra opción (dieser; jener; der), alternativa, por antonomasia, a la repetición superflua. Y más aún, el adverbio pronominal constituye un grupo de elementos muy importante en la investigación de la Lingüística Textual ${ }^{8}$, pudiéndose emplear tal como los pronombres personales y sus derivados como constituyentes deícticos anafóricos o catafóricos, independientemente de la relación de hiper- e hiponimia:

5 Das SS-Gefolge (también SS-Helferinnen) es una construcción que surgió durante el nacionalsocialismo y hacía referencia al personal femenino de ayuda a la SS

6 Del prefijo Zu+Hilfe y el confijo -nahme, que a su vez forma otras tantas construcciones: Abnahme, Einflussnahme...

7 Las posibilidades son además infinitas: im Verfolg + Gen.; im Vorfeld + Gen.; im Wege / im Zuge + Gen.; auf dem Hintergrund + Gen.; im Verfolg + Gen.; mit Ausnahme + Gen.; nach Ausweis + Gen.; in Ansehung / in Rücksicht + Gen.; im Anschluß an + Akk.; in Anlehnung an + Akk.; im Hinblick auf + Akk.; in Beziehung auf + Akk., etc.

8 Mediante la que se ordenan las secuencias que definirán las tipologias de lenguas.

Futhark 8 (2013) Castro, La evolución de las "Stammbildungen", 69-85

ISSN 1886-9300 
"Ein Jahr ließen sie inn auf seinen Prozeß warten. Die Hoffnung trog, daß die Sowjets 1 unter dem Druck der Carterschen Menschenrechtsoffensive den Gründer der Moskauer Helsinki-Gruppe 2 vorher freilassen und in den Westen abschieben würden. Am Pfingstmontag stellten sie ${ }_{1}$ den Atomphysiker und Bürgerrechtler Jurij Orlow 3 vor Gericht..."

(Cit. Klaus Brinker 2005: 35, en : Die Zeit v. 19. 5. 1978)

De tal modo, tanto el segmento 1 (sie - die Sowjets) como los segmentos 2 y 3 serían de tipo catafórico (ihn, seinen - den Atomphysikerund Bürgerrechtler J. O.). Los segmentos 2 y 3 son, por una parte, catafóricos (den Gründer der... - den Atomphysiker... J. O.), por otra parte, anafóricos (die Sowjets - sie). Cabe destacar que la misma estructura textual sería posible en español, quizás no tanto en inglés.

Actualmente, y por referirnos a un ejemplo más concreto, en Suabia y Franconia, los pronombres más coloquiales han ido extendido las formas del nuevo alto alemán de ihr (<ahd. y mhd. ir), dando lugar a formas que no se dejan delimitar fácilmente en la confrontación de los diptongos (iar) y monodiptongos (iir). En el Norte de Suabia es empleado ui en lugar de wir. La extensión funcional de este pronombre es singular, pues es llevada al extremo: así se dice uns lesen wir en lugar de wir lesen (cf. Erasmus-Kritzinger; Bowler \& Goliath 2000: 302). ${ }^{9}$ Un ejemplo más que puede originar confusión es enk, una mezcla de ees (Hochdeutsch: uns) con las formas geográficamente más cercanas $d_{i}$ ts/deeds, por lo que las formas enk $\mathrm{a}_{\mathrm{a}}$ hujier, aich $\mathrm{a}_{\mathrm{a}}$ tan sólo derivan parcialmente de los polisilábicos pronombres posesivos ihre, ihrer.

Conforme a los criterios de la Lingüística Textual los sustantivos reanudan la relación de continuidad discursiva de manera lógica ("begrifflich", p. ej. eineNiederlage: der Sieg; ein mühsamer Aufstieg: der Abstieg; ein Problem: die Lösung; eine Frage: die Antwort), ontológica ("naturgesetzlich", p. ej. ein Blitz: der Donner; ein Mensch: das Gesicht; ein Elefant: der Rüssel; ein Kind: die Mutter), y cultural razonada ("kulturell begründetes Kontiguitätsverhältnis", p. ej. eine Straßenbahn: der Schaffner; eine Stadt: der Bahnhof; eine Kirche: der Turm; ein Haus: die Türen; ein Krankenhaus: der Chefarzt). Muestran su transcendencia lingüística a través de fenómenos de inmanencia (sustitución por sinónimos, relaciones de hiper- e hiponimia y de contigüidad, cf. en Wood 2001: 99-104).

En cuanto a las relaciones arriba indicadas exponemos algunas palabras que consideramos llamativas:

- Taufe: Taufpatin (esp. madrina) - Taufpate (esp. padrino). La palabra femenina Patin no es separable en todas las regiones del masculino, un hecho ya

9 Véanse en español las abundantes estructuras del tipo noshemos leído/estudiado el temario donde el "dativus commodi" parece un recurso meramente estilístico.

Futhark 8 (2013) 
manifiesto en nuevo alto alemán, con la distinción de artículo der Pate / die Pate, algo que no es nuevo, pero que sí da lugar a curiosas formaciones. Compárese en este sentido el conservadurismo español en las denominaciones profesionales consideradas masculinas que tan sólo en los más recientes tiempos empiezan a cambiar (el / la juez, el / la médico).

- Geschlecht: Götte-Gotte (esp. hombre - mujer). De ahí que en alemán medio también existiera götte / gotte para mostrar ambos géneros y que estas formaciones hayan originado los "compuestos de evolución"Rockdootle Hoosedootle.

- Essen: Frühstück - Vesper (esp. desayuno - merienda). Y que palabras como Frühsuppe, Morgensuppe, Morgenkaffee, Frühkaffee sean empleadas en "Fichtelgebirge" (Oberfranken), con la singularidad de que designan la segunda ingestión del día y no la primera como se piensa, por lo que serían equivalentes a Vesper y no a Frühstück (cf. Duden 2003: 57).

- Waschen: Trog (esp. lavadero). Y que asimismo Trog o Waschtrog (Wåschdrouch, Droog, Druug) sea mezcla de dos raíces posiblemente existentes *drû- "Baum" y *-ga, que expresaba o bien la pertenencia a un árbol o se refería al árbol en diminuto. Si, en efecto, de ello no hay absoluta certeza.

Un dato muy curioso es que precisamente las "transformaciones absolutas" que se realizan a nivel pronominal sean las que podamos encontrar a nivel morfemático, tal como ocurre en los diminutivos, convirtiéndose así éstos en un combinado de difícil descripción: p. ejemplo Hundlan, Hundle -formas procedentes de la flexión débil, y de las que deriva Hundl, con pérdida vocálica- o Hundlich -forma procedente de un sufijo colectivo que nos remonta a la época del alto alemán medio -. Y las más diversas variantes dialectales Hundai (Este y Suroeste de Baviera) o Hunderl, de donde surgen las terminaciones -erl (Lüngerl, Wammerl, Schwammerl, Stamperl, Stüberl) y otras acabadas en -le y -la -Hundle o Hundla-, más típicas del Oeste de Baviera. El resultado más llamativo de estas múltiples combinaciones es quizá la marcación del plural, la cual sí tiene su origen directo en las raíces de las palabras, de lo que se obtiene Hondle-Hondle en Suabia Media -aunque igualmente existan Hundla -Hundlan en Lechrain y Hundla -Hundlich en algunas partes de Franconia- (cf. Cameron 2005: 485).

Muchos son los ejemplos mencionables en cuanto a adverbios que muestran controversia. Nombramos a modo de ejemplo los pares iiwaiiwi y rom - nom (herüber - hinüber), que casi nos recuerdan a "alguna que otra palabra hawaiana" o "al sonido onomatopéyico de la moto". O rauf - nauf y auf - auffi (herauf - hinauf), ciertamente más moderado (cf. Kluge 1995: 102).

Futhark 8 (2013) Castro, La evolución de las "Stammbildungen", 69-85 ISSN 1886-9300 


\section{Formas congruentes de expresión de la temporalidad}

En las formas verbales destacan normalmente las adaptaciones ortográficas. Nos ha llamado particularmente la atención que se produzcan tan sólo a través del contacto con el idioma inglés y que ello dé lugar a la fusión morfofonética de verbos como scannen > gescannt, plotten > geplottet y trampen > getrampt (y oraciones del tipo vor dem Spiel war er völlig relaxt versus Siemens hat weitere Bereiche outgesourced [actualmente se lee con más frecuencia: outgesourct]). Claros préstamos hubieran sido en el idioma castellano estresar, noquear, escanear o en catalán estressar, driblar-se, noquejar ${ }^{10}$,incorporándose en ambos idiomas, como no puede ser de otra manera, a la clase de verbos en -ar con todos los efectos morfológicos que esto implica ${ }^{11}$. En la adaptación surge un nuevo parentesco entre los idiomas románicos y el alemán: por ejemplo ¿hast du gescannt? / ¿has escaneado?.

Asimismo revela el verdadero sentido del presente artículo las posibilidades de prefijación de beshoppen, abshoppen, einschoppen, ergoogeln, nachgoogeln, que ponen de manifiesto la problemática de los preverbios separables e inseparables del alemán y sus terminaciones, por ejemplo, si intentara formarse el participio perfecto (infijo -ge en caso de verbos separables: nachgegoogeltversus ergoogelt, en contraste a préstamos de procedencia latina: ausmanövriert y vermanövriert). Es evidente que los verbos prestados del inglés se incorporan al léxico alemán como nuevos radicales a todos los efectos y eso origina que en este caso en alemán se elimine la diferencia entre palabra "heredada" y "prestada".

10 No nos extenderemos en ejemplificar los fenónemos propios de los sustantivos, pues muchos de ellos se derivan de las mismas acciones verbales y son asimilados normalmente: así en las realizaciones del fonema [i] y del "schwa" (p. ej. en cast. mitin - ingl. meeting-, pirsing - ingl. piercing, catalán míting - ingl. meeting, lísing - ingl. leasing), en las sustituciones de $y$ por $i$ (p. ej. en cast. y cat. derbi ingl. derby), en las sustituciones de $k$ por $q$ (p. ej. en catalán rànquing - ingl. ranking, pàrquing - ingl. parking[lot], màrqueting - ingl. marketing), en las sustituciones de sh y ch por $x$ (p. ej. en catalán xèrif - ingl. sheriff, xip - ingl. chip), en la misma introducción del acento ( $p$. ej. en cat. xèrif o en cast. córner), y las introducciones de la mayúscula en alemán (p. ej. Computer, Laptop).

11 En cualquier caso parece que tanto en los idiomas románicos como en alemán las propias normas morfológicas se imponen con más insistencia en cuanto se trate de verbos (p.ej. el prefijo / infijo ge- en los participios del pasado alemanes). Este es un hecho evidente, considerando que es la categoría que más actividad flexiva exige.

Futhark 8 (2013)

Castro, La evolución de las "Stammbildungen", 69-85

ISSN 1886-9300 


\section{Entradas de estructuras secundarias y adjetivos. Consecuencias traductológicas: especial atención a las formaciones cruzadas y confijadas}

Otros compuestos de entrada en verdaderas estructuras secundarias son: en alemán Allroundspieler, teamfähig, Handwerkerjob, abchecken, anturnen, auftunen, recycelbar; en castellano esnifada, rockero, rapero, estresante y catalángolejada. (cf. Rüdinger 1992:143ss.). Coinciden en su mayoría con compuestos por derivación y entradas con preverbios. Normalmente los compuestos de entrada adjetival también encuentran su adaptación en construcciones mixtas del tipo der toughe Juniorchef o die hippe Veranstaltung, con la tendencia a suprimir en castellano género y/o número en contra de sus propias costumbres gramaticales, como ocurre en asignatura light - pl. asignaturas light. ${ }^{12}$ Son neologismos (cf. en relación Hartmann 1991; Jule 2005 y Kormos 2006), y puede ocurrir cualquier cosa.

En términos traductológicos la justificación de conceptos neológicos de carácter específico y relativos a distintos campos no siempre es fácil: en enseñanza, técnica, sociedad, turismo, etc., las formaciones podrían ser discutibles por sus equivalencias (cf. Fleischer \& Barz 1995):

Bundeskanzlerin: "la canciller alemana" o "la presidenta de gobierno alemana", Mehrsprachigkeit: "plurilingüismo" -pareciendo haberse elaborado al albedrío-, Standortkonkurrenz: "competitividad lugareña", Zentralabitur: "bachillerato central", Ampelkriecher: "dominguero de ciudad" Hochseilgarten: "jardín de cables altos" essemessen: "simsear", School Talker: "ponente escolar" skypofonieren, skypen: "skypear" Sturmtränen: "lágrimas tempestivas", Akkulturationsbemühung: "esfuerzo de aculturación", Hoscar: el "hoscar" (premio a la mejor hospedería o albergue en Alemania).

La dificultad de la traducción varía en función de: a) la existencia, respectivamente, constancia del hecho en cuestión en la lengua de destino; se suele buscar aquí un equivalente funcional (presidente de gobierno) o asonante al concepto de origen (canciller) b) la estructura aplicada al referirse al mismo hecho es diferente en la lengua de destino (Standortkonkurrenz: existen ubicación y competencia como traducciones literales de los elementos del compuesto alemán. No obstante, competencia de ubicación no genera el mismo sentido, aunque el hecho al que se refiere la palabra alemana sí es conocido en español: atracción de inversiones). Un buen ejemplo de que parentesco y/o equivalencias a

12 Curiosamente un caso de convergencia al revés por parte del español que, tratándose de un préstamo de procedencia inglesa, suprime la concordancia del adjetivo adyacente.

Futhark 8 (2013) Castro, La evolución de las "Stammbildungen", 69-85

ISSN 1886-9300 
nivel de radicales no garantizan el acierto respecto a estructuras más complejas.

Otro ejemplo sería el término low cost, que a veces se traduce por bajo coste y en otras ocasiones suele dejarse tal cual en inglés: LowCost Fahrzeug: modelos low cost-Billiganbieter, en esp. suministrador de bajo coste- low cost. Ello da una imagen de desorden, por lo que pensamos que convendría unificar su uso.

Bajo el lema "Ostalgie" se explica muy bien el fenómeno de la combinación o Wortkreuzung, cruce entre Osten y Nostalgie, fenómeno también observable en lenguas románicas ( $p$. ej. cat. eurofória formado de Europa y eufória), si bien dicha explicación no se aplica siempre para otros sustantivos que presentan el mismo proceso:

Bionik Hand: mano biónica, cruce entre Biologie y Technik. Nettikette: etiqueta de la red, -cruce entre Net(z) y Etikette-, Bistronomie: del cruce entre Bistro y Gastronomie, der Teuro: el euro relacionado con la carestía de la vida unión deEuro y teuer-, das Hostel: hotel nostálgico del este -unión entreOsten y Hotel-...

En este sentido son también problemáticos los procesos de reducción, que según Ramón Almela Pérez (1999: 91-97), podrían englobarse dentro de la combinación de los procesos de acrónimos y siglas. Los acrónimos serían, en este caso, lo que corresponde a los llamados "términos reducidos parciales", p. ej. Telekom (<Telekommunikation). De igual modo, en alemán hay interpretaciones o clasificaciones diversas del mismo proceso como "Wortkreuzung" y "Kurzwortbildung".

Todos estos ejemplos contrastan con otros muy conseguidos en la tradución de Carmen Gierden et altri en el libro "Deutsche Neubildungen". Destacamos algunos de ellos:

"der Typ gemolkene Kuh: la gallina de los huevos de oro (pág. 130), Nachahmermedikament: medicamento genérico (pág. 135), Rinderwahnsinn: enfermedad de las vacas locas (pág. 136), Vogelgrippe (pág. 139): gripe aviar, Copy-Paste-Syndrom: el síndrome del copia y pega (p. 143), Quadfahren: ir en quad (pág. 186)".

(Cit. en Carmen Gierden 2010)

Será por un fenómeno similar que algunos autores identifiquen el proceso de "Yuxtaposiciones" o "Zusammenrückungen" en algunas entradas (Hilflos-ausgeliefert-Sein, p. 164) y- sin aparente razón -no así en otras similares (No-go-Area, p. 129, Geiz-ist-geil-Mentalität, p. 164, Sonneund-Strand-Land: país destino turístico de sol y playa, p. 172, vid. Biber 1998: 32; Baron 2000: 121; Gierden et altri 2010).

También nos llama la atención la catalogación de los confijos como "unidades léxicas que en la lengua actual han ido perdiendo su autonomía léxica y siempre se combinan con otra unidad léxica a la que prece-

Futhark 8 (2013) Castro, La evolución de las "Stammbildungen", 69-85

ISSN 1886-9300 
den como confijo inicial o, en posición final, como confijo terminal" (cf. Gierden 2010: 44). Efectivamente la definición ya no afecta a elementos como -körper, -kraft, -werk, -zeug, y otros que hoy en día presentan auténtica autonomía léxica, aunque continúan estando clasificados como confijos (Gierden 2010: 45). Por este mismo motivo resultan muy controvertidos. Asimismo parece dificultoso establecer la diferencia de los confijos prestados introducidos por Hyper- Meta- Mini- Mikro- Trans-, entre otros, con los prefijos de origen latino o griego. Sánchez (2011) se manifiesta de esta manera en torno ala "polémica":

"Esta cuestión es naturalmente muy debatida y discutida entre los lingüistas y dependiendo de unos o de otros, el fenómeno recibe nombres diferentes y engloba a términos también distintos. De ese modo, en la entrada Megaerfolg, (p. 127) Carmen Gierden considera Mega- prefijo cuando, en la exposición de la formación de palabras, los autores lo clasificaron como confijo"13

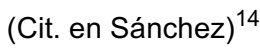

\section{Generalización de los resultados}

Nos hemos basado para nuestro análisis principalmente en las lenguas románicas -español y catalán, básicamente- y germánicas -alemán e inglés-, al considerar que éstas son altamente representativas de la temática que se expone. Pero pensamos que las variantes de las lenguas han contribuido notablemente a facilitar muchas de las estructuras a las que se hace mención, y de las que dejamos constancia a través de las ejemplificaciones; de tal modo, las subvariedades del bávaro han supuesto, por su gran riqueza y valor expresivo, un avance a la hora de reflejar muchos de los argumentos. Asimismo nos hemos centrado en descubrir aquellas palabras que desde su origen y/o formación se prestan a confusión a la hora de establecerse un posible hermanamiento: efectivamente son casos "dudosos de interpretación", que con frecuencia pasan desapercibidos en los estudios contrastivos. A este fin se han delimitado las raíces de los neologismos, estableciéndose diferenciaciones entre préstamos, adaptaciones y otros elementos de importancia en la sintaxis textual.

En líneas generales, podemos afirmar que los principales cambios morfosemánticos y léxicos se han debido, unas veces, a las mezclas

13 Mega- (confijo) será en el sentido estricto de millón (Megawatt), mientras que sería prefijo en Megaerfolg (Mega- en el sentido de enorme).

14 URL: http://readperiodicals.com.

Futhark 8 (2013) Castro, La evolución de las "Stammbildungen", 69-85

ISSN 1886-9300 
idiomáticas de difícil reconocimiento, otras veces, a la simple deducción de posibilidades, asimilándose las características de una segunda y/o tercera lengua, mayormente el inglés, sin existir un criterio uniforme en los planteamientos, un hecho que tiene repercusión directa en los calcos lingüísticos y en las traducciones. Por su parte, a modo teórico, se ha pretendido extender y vincular la concepción de "lenguas emparentadas" a la dialectología, por considerarse que los factores de evolución-cognición están directamente relacionados con las nuevas formaciones, no siempre predecibles.

Cabe destacar, sin embargo, que el concepto de parentesco convencional, tal como se expresó en el resumen, habrá que modificarlo en algunos detalles:

Por un lado, se desprende que el parentesco entre diferentes variedades del mismo idioma se hace patente en la medida en que se atiende a determinadas pautas generales de la lengua en cuestión (p.ej. morfema $-\varnothing$ en los plurales de diminutivos en alemán). El mismo fenómeno se denota en los préstamos ingleses de "nomina agentis" (computer, manager), siguiéndose en este caso las normas alemanas y no las inglesas para este tipo. En este supuesto es el idioma inglés el que actúa en contra de su parentesco histórico con el alemán.

Por otro lado, en cuanto se adaptan formas dialectales al alemán estándar (p.ej. Mädel, Jung), respectivamente en la incorporación de extranjerismos, pseudo-extranjerismos y formaciones innovadoras (Ossi, Wessi), se observa una clara tendencia asimilar la $-s$ como morfema único de plural, lo cual establece un parentesco de nuevo tipo entre inglés, español y alemán.

El español, además, renuncia a su habitual concordancia en número y género en cuanto a adjetivos prestados se trate (light), acercándose de tal manera a las condiciones morfo-estructurales de la lengua de origen.

En lo que se refiere a los verbos procedentes del inglés (escanear scannen) hay una clara preferencia de "españolización", respectivamente "alemanización", en el sentido de que en ambos idiomas se incorporan a todos los efectos en las clases de conjugación más regulares (verbos en -ar en caso del español, conjugación débil en alemán). Aunque esta intervención efectivamente lleve a formas distintas, existe un mismo planteamiento genérico en el trato, la incorporación morfológica menos complicada.

Conforme a los planteamientos expuestos podemos concluir que existen al menos dos tipos de parentesco, uno según el planteamiento tradicional que tiene su base en movimientos diacrónicos internos, y otro que se debe a ciertas tendencias convergentes, precisamente a raíz del contacto sincrónico. 


\section{Referencias bibliográficas}

ALMELA PÉREZ, R.: La formación de palabras. Madrid: Taurus, 1999.

BARON, N.: Alphabet to Email: How Written English Evolved and Where it's Heading. London, Routledge, 2000.

BIBER, D.: Variation across Speech and Writing. Cambridge, UP, 1998.

BRINKER, K.: Linguistische Textanalyse. Eine Einführung in Grundbegriffe und Methoden. Erich Schmidt: Berlín, 2005.

CAMERON, D.: "Language, Gender and Sexuality: Current Issues and New Directions" en Applied Lingusitcs Journal, 2005, Oxford University Press, 20(4), págs. 482-502.

DUDEN: Redewendungen und sprichwörtliche Redensarten Wörterbuch, Mannheim, Duden, 2003.

ERASmus-KRITZINGER, L.E. / BOWLER, A. / Goliath, D.: Effective Communication. Pretoria: Afritech publishers, 2000

FLEISCHER, W. I BARZ, I.: Wortbildung der deutschen Gegenwartsprache, Tubinga, Nyemeyer, 1995.

Gierden Vega, C. / Eggelte, B. / Heinsch, B. / Hofmann, D.: Compendio temático de neologismos Alemán-Español: Deutsche Neubildungen, Stuttgart, 2010.

GLINZ, H.: Grammatiken im Vergleich: Deutsch - Französich - Englisch - Latein; Formen - Bedeutungen - Verstehen. Tubinga: Max Niemeyer, 1994.

HARTMANN, R.K.K.: Sociology of the Dictionary User: Hypotheses and Empirical Studies. In Hausmann, F.J. et.al. (eds.), Berlín, Walter de Gruyter, 1991.

JULE, A.: Gender, Participation and Silence in the Language Classroom, Oxford University Press, 2005

KÖNIG, W. / RENN, M.: Kleiner Bayerischer Sprachatlas, Deutscher Taschenbuch Verlag, 2006.

KoRMOS, J.: Speech Production and Second Language Acquisition. Lawrence Erlbaum Associates, 2006.

KLUGE, F.: Etymologisches Wörterbuch der deutschen Sprache. Berlín, Nueva York, 1995.

MANTEUFEL, A. / SCHIEPEK, G.: Systeme spielen. Selbstorganisation und Kompetenzentwicklung in sozialen Systemen, Göttingen, Vandenhoeck \& Ruprecht, 1998.

MATURANA, H. R.: Biologie der Realität, Francfort del Meno, Suhrkamp, 1998.

NAPOLI JO, D.: Linguistics, Oxford University Press, 1996.

OKSAAR, E.: Zweitspracherwerb. Wege zur Mehrsprachigkeit und zur interkulturellen Verständigung, Stuttgart, Kohlhammer, 2003.

ORWIN, R.G.: "Evaluating Coding Decisions", en The Handbook of Research Synthesis, New York, Russell Sage Foundation,1994, 4, págs. 62-139.

RÜDINGER, K.: Aktuelle Wortbildungen im Bereich der katalanischen Pressesprache, Bibliothek des Intituts für Romanistik: Erlangen, 1992.

SudO, J.: "Teaching New Tendencies in Gender Usage in Modern English", en ELT Journal, 2007 Oxford, University Press Volume 61II, págs. 35-45.

THEO, E.G. / CUTTER, M.A.: Why can't the English: An analogy of admirable and execrable English. Basterville, Hugh Keartland (Pty) Ltd., 1971.

Futhark 8 (2013) Castro, La evolución de las "Stammbildungen", 69-85

ISSN 1886-9300 
TRAUB, R.E.: Reliability for the Social Sciences: Theory and Applications, Thousands Oaks, CA, Sage, 1994.

TRUDGILL, P.: Sociolinguistics: An Introduction to Language \& Society. Londres, Cox \& Wyman Ltd Press, 2007.

WAZLAWICK, P. et altri: Menschliche Kommunikation. Formen, Störungen, Paradoxien. Berna, Stuttgart, Viena, Hans Huber, 1990.

WIESINGER, P.: Phonetisch-phonologische Untersuchungen zur Vokalentwicklung in den deutschen Dialekten, 3 Bde. Berlín, 1970.

WHORF, B. L.: Sprache - Denken - Wirklichkeit. Beitrage zur Metalinguistik und Sprachphilosophie. Reinbek: Rowohlt (Rowohlts Deutsche Enzyklopadie, 174), 1963.

WooD, J.: Gendered lives: Communication, gender, and culture (4th Edition), Belmont, CA, Wadsworth Publishing, 2001.

YULE, G.: The Study of Language. Cambridge University Press, 2007.

Futhark 8 (2013)

Castro, La evolución de las "Stammbildungen", 69-85

ISSN 1886-9300 
Futhark 8 (2013) Castro, La evolución de las "Stammbildungen", 69-85 ISSN 1886-9300 